\title{
VICENTE HUIDOBRO E AS INTERPRETACIÓNS DA VANGARDA EN GALICIA \\ Os exemplos de Montes, Risco, Castelao e Manoel Antonio
}

Por

EVA VALCÁRCEL

\section{EUXENIO MONTES, ADMIRADOR E SEGUIDOR DE HUIDOBRO}

O escritor de Bande, cecáis polo seu cosmopolitismo, cecáis polas frecuentes estadías no extranxeiro parece comprender ben el arte nuevo. A renovación estética na obra de Montes convive, como parece ser o signo da vanguardia poética galega, con estructuras tradicionais, pero existe unha vontade de comprensión das novas estéticas e una información de que se está a facer en Europa. Montes mestura renovación e tradición en 1930, cos Versos a tres cás o neto ${ }^{1}$ onde ensaia co versolibrismo, e co caligrama no poema titulado «Ourense. Miño». Comparte con Huidobro o interese por Nietzche, e a participación nas tertulias de Pombo e do Colonial, a Cansinos e a Gómez de la Serna. Tamén a amistade de Guillermo de Torre que o chamou «amante do corazón de Dadá».

Gerardo Diego calificou a Montes como «fervoroso huidobrista de aquella época» e agradécelle que lle tivese prestado os volumes da obra do chileno, de onde Diego copiou os textos. No poema «Creacionismo» de Gerardo Diego, o poeta recrea en verso a teoría dos manifestos de Huidobro e dedícalle o poema a Montes, «mi Virgilio»².

\footnotetext{
${ }^{1}$ A Coruña, ed. Nós, 1930.

${ }^{2}$ Cfr. Eva VALCÁRCEL, Cuadernos de Estudios Gallegos, n 103, Santiago, 1989.

"CUADERNOS DE ESTUDIOS GALLEGOS", Tomo XLVI, Fascículo 111, Santiago 1999.
} 
O poema di «Modelemos, creemos nuestros lunes, nuestro martes y miércoles, nuestro jueves y viernes» e tamén «con las derruidas piedras levantemos de nuevo nuestros mundos».

As resonancias do «Non serviam» (1914) de Huidobro son evidentes. Manifesta Huidobro: «El poeta dice a sus hermanos: 'Hasta ahora no hemos hecho otra cosa que imitar el mundo en sus aspectos, no hemos creado nada...' Y hemos cantado a la naturaleza (cosa que a ella bien poco le importa) Nunca hemos creado realidades propias».

E en «La creación pura» (1921) recalcará esa idea:

«No se trata de imitar la Naturaleza, sus exteriorizaciones, sino de hacer como ella; no imitar sus exteriorizaciones, sino su poder creador».

Colaborador de Grecia, Cervantes e Revista Casa América Galicia, Montes tamén publicou polo menos dous poemas en Ultra de Oviedo. Un deles «Crepúsculo invernal», de 1919, ten unha disposición cubista, de discursos paralelos, constituíndo unha unidade poemática construída de fragmentos de diferentes discursos, que inclúen o caligrama. Asimesmo podemos comprobar a novidade das imaxes creadas desde a analoxía, as imaxes do mundo que o poeta crea fóra do que existe, as imaxes do mundo que debera existir, tal e como Huidobro adelantara en «La creación pura».

En Grecia, en 1920, publica Montes outro poema decididamente cubista, «Five o'clock tea». O título pertence a Pierre Reverdy, que no seu libro $L e$ cadran quadrillé de 1915, inclúe o título «Five o' clock». Os versos proporcionan diferentes espacios para a contemplación: terra, mar, praia. E o conxunto está observado cunha mirada xeométrica case, desde arriba percibíndose ben os volumes.

A Vicente Risco dicaralle o «Atardecer en New York» tamén de 1919, publicado en Grecia. E un poema urbano cunha sintaxe xeometrizante, cunha técnica de collage, con aire cinematográfico, onde se expresa a vida no ventre dunha gran cidade coas persoas apiñadas, encamiñándose aos horizontes de formigón. O léxico non nos é estraño, pertence a ese mundo novo da vangarda, progreso, técnica, cosmos celeste e urbano ${ }^{3}$.

\footnotetext{
${ }^{3}$ Para unha análise detallada dos poemas, Vid. Eva VALCÁRCEL, Cuadernos de Estudios Gallegos, $\mathrm{n}^{\circ} 103$.
}

"CUADERNOS DE ESTUDIOS GALLEGOS", Tomo XLVI, Fascículo 111, Santiago 1999. 


\section{A PERSONALIDADE VANGARDISTA DE VICENTE RISCO}

Vicente Risco fixo de crítico literario de Montes en A Nosa Terra. Risco, que xa escribira o «Preludio a toda estética futura» e xa tivera ocasión de definir o futurismo e a súa postura fronte a modernidade, daba a coñecer «Esquematizacións fantesistas»e «Neve», do escritor de Bande, relacionando con Huidobro e ensinando a mirar a nova estética e as imaxes creadas do cubismo e o creacionismo:

«Os poemas que hoxe pubricamos de Euxenio Montes están feitos na escola creacionista, fondada polo poeta chileno Vicente Huidobro e polos frenceses Cendrars e Reverdy. Nelas non se deben buscar as imaxes habituais, coñecidas, á primeira ollada verificabres; hai que ter en conta (...) que eiquí, as imaxes son creadas direutamente polo poeta e non tomadas do falar corrente, senón impregnadas eiquí por primeira e derradeira vez».

O didactismo de Risco lévao, como o fixo despois Huidobro en «El Creacionismo» a exemplificar coas imaxes, distinguindo «Baixan puntas d`estrelas» coma imaxe creada. Engade Risco que unha imaxe creada e real e ademais e eterna: «é unha imaxe eterna que queda como Hércules de Lisipo, coma Victoria de Samotracia».

Poderíase relacionar esta teoría coa de Huidobro, incluso coa expresión mesma da diferencia entre a verdade da vida e a verdade da arte: « La Venus de Milo es una verdad de la vida que remite a la belleza femenina, una mesa posee verdad de arte, no remite sino a la imagen creada y es eterna».

Como sabemos Risco propuña no ano 1917, no preliminar de La Centuria unha denuncia contra da guerra, nunha estética antifuturista, ademais de encontrar que era o momento de «romper el ritmo habitual del pensamiento». Así se retrata a sí mesmo coma un home moderno, inscrito no século. Así se corrobora nas preocupacións que como intelectual amosa no «Preludio a toda estética futura» ${ }^{4}$. Destaca aquí a súa interpretación do concepto do moderno como un resultado de evolución, pero no que tamén

${ }^{4}$ La Centuria, $\mathrm{n}^{\circ} 1,2,3,5,6,7$. Existe unha edición facsimilar da revista, publicada por Sotelo Branco en 1981.

"CUADERNOS DE ESTUDIOS GALLEGOS", Tomo XLVI, Fascículo 111, Santiago 1999. 
teñen importancia as estéticas de fines do século XIX, simbolismo e decadentismo. Iso lévao á definición da súa postura estética mestura de beleza harmónica clásica e técnica, desmarcándose da estética do antiarte dos futuristas. Parece que plantexa no seu discurso o problema vangardista da verdade da vida e a verdade do arte. Así el ve a Venus de Milo (verdade da vida para Huidobro) coma a media aritmética entre a máquina de afeitar (verdade do arte) e un anxo do Beato Angélico. Recoñece os valores do clasicismo e elixe ver neles a imaxe da beleza da técnica, mais non do progreso. Risco non lle concede o futurismo demasiada orixinalidade ou seriedade e calificao de vello.

O mesmo fixo Huidobro, aínda que despois utilizase a técnica dos de Marinetti para perfeccionar as súas imaxes creadas. Hai que sinalar que no Prefacio a Adán (1916) o chileno presenta a necesidade de escribir a Estética del futuro e amosa as súas notas sobre o tema. En ese ensaio, Huidobro explica a necesidade do concepto da unidade poemática, na que funciona un só verdadeiro ritmo, pero aínda máis o poema no «lo hacen los ritmos sino el pensamiento creador del ritmo»e recoñece no poema «una arquitectura propia»

Con respecto o Futurismo as razóns expostas por Risco e Huidobro non defiren daquelas de «Futurismo y maquinismo», que en 1909 Rubén Darío explicara. Dase una converxencia de fontes e ideas. Hai que dicir que Huidobro sigue o pé da letra a exemplificación de Darío. Traduce os once puntos de Marinetti e comenta que o valor, a violencia estética xa están en Homero e con respecto a comparación entre o «automobile da corsa e a Victoria de Samotracia», opinan ironicamente: «¿Qué es más bella una mujer desnuda o la tempestad? ¿un lirio o un cañonazo?». A conclusión e a mesma para os tres: $\mathrm{O}$ futurismo e vello, por presentarse como descubridor de todo. Importante e sinalar a idea da creación fronte a antiga representación ou mímese, postulado básico de toda a vangarda.

En 1920, Risco pronunciou a conferencia «Arte Nova» ${ }^{5}$, con motivo da exposición de Castelao na Coruña. Alí explica o cubismo e da a coñecer as lecturas e a información que xa tivo do movemento. Risco leva a cabo unha reflexión artística, amén de política noutros apartados, que inclúe as seguintes ideas:

${ }^{5}$ A Nosa Terra, A Coruña, 20 de marzo de 1920.

"CUADERNOS DE ESTUDIOS GALLEGOS", Tomo XLVI, Fascículo 111, Santiago 1999. 
Existen tres graos de contemplación da realidade denominadas realista, estética e intelectiva:

«A pirmeira, a contempración realista, busca a realidade da cousa, a súa entidade sustancial, o seu ser.(...) e pódese conformar coa realidade aparencial... apreciable polo senso da vista, pro podese non conformar coa realidade aparencial e pode andar a ver s'atopa a realidade fonda, interna, coma si dixéramos estructural, ou tamén arquitectural da cousa contemprada, i eiquí témolo cubismo.

Polo tanto, o cubismo é realista e busca a entidade substancial das cousas máis dentro da sua aparencia sensible, na súa estructura, na sua construcción interna e para resolver ese problema non sirve a perspectiva de Leonardo que non se ocupa mais que das superficies e di:

«Coas figuras que pintan os pintores tradicionales pasa coma ca lúa: nunca lle vémo-la parte d'atrás»

Huidobro, pola súa parte, case no mesmo momento, en 1921 na conferencia, «La creación pura», expón dun xeito parecido as distintas fases da relación entre o mundo e a arte. Alí explica que a arte pode presentarse baixo tres aspectos: «Arte inferior al medio (arte reproductivo), arte en armonía con el medio (arte de adaptación) y arte superior al medio (arte de creación)» Así mesmo distingue para cada parte un segundo esquema que resume a evolución de cada unha das épocas antes enumeradas:

«Predominio de la inteligencia sobre la sensibilidad

Armonía entre la sensibilidad y la inteligencia

Predominio de la sensibilidad sobre la inteligencia.»

No mesmo texto fala da intelixencia e a intuición fronte a sensibilidade.

Vicente Risco di que o cubismo consiste en descompoñe-la realidade nos seus elementos esenciais e recompoñe-la seguindo unha norma, arbitraria, inventada. Nomea a Picasso, a Gris, a Metzinger, posiblemente lera algo de Gris. Fala dos elementos de forma.

Risco teoriza sobre o cubismo analítico, e parte de Cezanne: «Cezanne resumía toda a súa arte nunha verba realizar. Crear unha nova realidade, percibila realidade atrás das aparencias sensoriais, descompoñéla realidade visibel pre recompoñéla artísticamente...»

"CUADERNOS DE ESTUDIOS GALLEGOS", Tomo XLVI, Fascículo 111, Santiago 1999. 
O cubismo, creado por Picasso a partir de Cezanne, di Risco, descompón a realidade nos seus elementos esenciais, e recompona seguindo unha norma arbitraria. Fala do volume, de que a mirada do cubista da voltas ó redor do modelo e fai un análise e despois unha composición. Alude ó problema da perspectiva tradicional, inservible para o cubismo e introduce o concepto de cuarta dimensión. E engade que a intención artística do cubismo e a creación pura e que o creacionismo de Huidobro é unha derivación literaria do cubismo. Parece que xa coñece a creación pura.

Á teoría, Risco une a práctica vangardista. E temos un bo exemplo de técnica creacionista cubista en «Ujuju...». ${ }^{6} \mathrm{O}$ poema e recordado en «Arte Novo», alí di que «Galicia é unha entidade criadora no alborexar da nova civilización atlántica e que Vigo e A Coruña son pontos de tensión máxima gracias as necesidades do comercio universal». Este poema goza de unha absoluta unidade intelectual encerrada entre os versos marco: terra/terra. Ten un léxico vangardista que cas imaxes analóxicas acércanos ó mundo do progreso e a unha profecía.

Coma no poema de Montes ou nos de Huidobro, elimínase o anecdótico e o descritivo, prodúcese instantaneismo ou suspensión de nexos innecesarios, dase a montaxe verbal, a práctica combinada de letras de diferentes tamaños para acentuar palabras; ten, como diciamos, unha unidade de composición e como o cadro cubista, bastase a si mesmo.

\section{CASTELAO E A INTERPRETACIÓN DA VANGARDA}

Se o anterior era o discurso estético e o exercicio poético de Risco na exposición de Castelao, pouco despois, este fai unha serie de observacións sobre o cubismo e sobre Picasso nun artigo que parece que ten vontade de dar a coñecer documentalmente a arte nova e o cubismo. Castelao, agás breves comentarios e dalgúns xuízos irónicos, non fai senón seleccionar fragmentos e así o expón el mesmo, dando bibliografía sobre o tema que el coñeceu tal vez fai pouco, na súa viaxe por Europa.

Castelao cita e traduce sucesivamente a Leonce Rosemberg, a Maurice Raynal, a Theo van Doesburg, a Pélédan, e por suposto a Albert Gleizes, pero sen convicción, coma el di:

\footnotetext{
${ }^{6}$ Para a análise dos poemas citados de Risco, Vid. Eva VALCÁRCEL, Cuadernos de Estudios Gallegos, $\mathrm{n}^{\circ}$ 104, Santiago de Compostela, 1991.
}

"CUADERNOS DE ESTUDIOS GALLEGOS", Tomo XLVI, Fascículo 111, Santiago 1999. 
«...expoñer de boa fe canto pudemos zugar ou apañar nos alleos, esquecéndonos de cantas ideas tivésemos deprendidas, pra dar con iso meirande sensación d'un convencimento que... ainda;non temos. Todo canto podamos dicir xa e ben coñecido por tódolos catadores catadores de arte en Europa; mais eiquí será descoñecido polos espíritus serodios, ou mal coñecido po ises avanzados que nos fan lembrar os xogadores de trinta e unha que sempre fan trinta e dúas».

Hai que dicir que a resoancia deste artigo entre os xoves artistas e relativa de acordo cas informacións que se extraen da Correspondencia ${ }^{8}$ entre Cebreiro e Manoel Antonio en 1922, alí dise que o cubismo perdeu importancia, que é vello e tamén que Castelao o estudiou a presa.

De Braque di Castelao que a súa obra «e un ouxeto creado pola forza da emoción que lle dou nascimento, é froito d'unha emoción creada sen suxeto nin fin, nin vontade de facela, é, o mesmo tempo, un fenómeno que non se relaciona con nada máis que coa súa propia sensibilidade», desestimando o papel da intelixencia e a intuición, fronte a sensibilidade.

Picasso non é moi comprendido por Castelao, como volveremos a ver no seu diario. Aquí Picasso é retratado como o que «iñora todo e asimila todo. A ialma de Picasso progresa aeito sin ningún fin determiñado, deixando facer ó fado sen chamar por il». O escritor galego amósase sorprendido porque Picasso «imita a Ingres», e «refusa o sentido común deixándose guiar polo xenio do absurdo», e tamén «dentro dil rifan a sua educación coa sua naturaleza: a forza do verdadeiro respeta as debilidades do ausurdo, e cicais pola debilidade da súa intelixencia desacougada e perspicaz perdeu dende fai tempo a fe ausoluta nos dogmas sempiternos do arte».

Estas e outras interpretacións de Castelao parecen confirmar que o cubismo e a vangarda quedan lonxe da comprensión e a aceptación de Castelao, xa que, en 1922, aínda que el di que «non se pode dar ainda unha definición do cubismo que evoluciona sempre e de tal maneira que hoxe a verba cubismo e un alcume nada máis», posúense experiencia e teorización necesaria para poder opinar, e mesmo neste ensaio danse elementos bibliográficos dabondo sobre o cubismo e ademais el tivo a oportunidade de ver en París na súa Viaxe por Francia Bélxica y Alemania as exposi-

\footnotetext{
${ }^{7}$ Nós, $\mathrm{n}^{\circ} 11-12$, xuño-agosto, 1922.

${ }^{8}$ Cfr Domingo GARCÍA SABELL ed., Manoel Antonio. Correspondencia, Galaxia, 1979.
}

"CUADERNOS DE ESTUDIOS GALLEGOS", Tomo XLVI, Fascículo 111, Santiago 1999. 
ción de Picasso e de ler os textos teóricos. Os mesmos textos nos que converxen Huidobro e Risco, por exemplo, cando falan das tres modalidades de acercarse a arte. ${ }^{9}$

En Castelao, as alusións a Platón non suscitan a reflexión sobre a Poética aristotélica coma a portadora dos valores do novo arte, porque supera o ideal platónico do poeta espello (Huidobro si o anotou). A mimese aristotélica ten o sentido orixinal grego de non reproducir a realidade como o fai a Historia senón crear a partir das leises que funcionan na natureza. Aristóteles está actualizado nos textos de Huidobro, pero tamén nos textos da pintura cubista.

Castelao critica o neoplasticismo, e o cubismo sintético, fala do cubismo puro e o espritu novo e introduce as teorías de Gleizes en torno o cubismo e a pintura.

No Diario $^{10}$ da súa viaxe, Castelao anota no día 24 de maio de 1921, algunhas opinións moi directas sobre Picasso e os cubistas que dan a medida da non aceptación da vangarda. Di, por exemplo, e sen moita explicación:

«Os cadros cubistas de Picasso son para volver tolo a calquera americano do Sul; pero unha persoa ben organizada espiritualmente e cunha tradición pesando enriba da súa raza, non pode tomá-los en serio, anque vexa que esa clás de pintura non sexa enteiramente inútil.»

Despois de anotar a existencia do cubismo sintético ó que denomina planista, recoñece Castelao que non pode entendelos: «Os cadros cubistas de Picasso pódese saber o que son se un se bota a adeviñar ( non se trata de saber ó que son, de velos coa mesma mirada do realismo mimético); pero os cadros planistas nen o mesmo demo podería entendelos». Os espidos, son «Nus que meten medo de grandes e mal feitos; os dedos das mans teñen sabañons tan abultados que a carnaza tápalle as unllas... Eu non podo

\footnotetext{
${ }^{9}$ Vid. as seguintes citas de Castelao, pertencentes ó mesmo artigo:

«O día que o homa cedendo ós empurróns dos sentidosm s'afaste dísta regla e chegu a e esquecela, o arte deixa de sere unha necesidade de crear, nascida dos empurróns do esprito, e convírtese $n$-un desexo de imitar.»

"Non se pode dar ainda unha definición do cubismo que evoluciona sempre e de tal maneira, que hoxe a verba cubismo é un alcume nada máis.»

«Agora Picasso imita a Ingres. ¡Home intresante! Picasso refusa o sentido común, deixándose guiar polo xenio do ausurdo».

${ }^{10}$ Ed. facsímil, Diputación Provincial de Pontevedra, Gráficas Portela, Pontevedra, 1981.
}

"CUADERNOS DE ESTUDIOS GALLEGOS", Tomo XLVI, Fascículo 111, Santiago 1999. 
supoñer que haxa persoa que sinceiramente poida decir que lle gosten istes mostros noxentos». Castelao fala en termos de gusto, de beleza, e usa polo tanto un criterio erróneo.

\section{MANOEL ANTONIO E A BUSCA DE NOVOS HORIZONTES}

$\mathrm{Na}$ correspondencia ${ }^{11}$ de Manoel Antonio vese un afán por relacionarse coas ideas que polo mundo están espalladas, un individualismo exacerbado, nietzcheano, como en Vicente Huidobro, e un desexo de ser moderno, amén das preocupacións pola terra.

Nas cartas busca información sobre creacionismo e cubismo, deféndese de ser ultraista e, finalmente, alguén lle debeu pasar os libros de Huidobro porque entre eles danse moitas converxencias. Ou en todo caso, puido ser que as teorías do cubismo o levasen polo mesmo camiño. No ano 1920, Manoel Antonio pedíalle por carta a Risco información sobre os movementos de vangarda. Risco fala de Huidobro, como de un amigo e ofrécelle un diccionario vangardista a Manoel Antonio. No ano 1922 Cabreiro fálalle a Antonio de Cendrars e faille unha interesante síntese dos postulados cubistas. O certo é que, finalmente, Manoel Antonio logrará una obra propia con moitas resonancias da vangarda, resonancias de fora de Galicia, huidobrianas, incluso nas propostas do «Mais Alá», na idea de non ser escravo (sino amo) da lingua, na fuxida da lei da costume, dos temas obrigados, do pranto e da elexía, da fotografía iluminada ou da literatura paisaxística. Ademais, o edificio léxico e imaxinístico de Manoel Antonio, o seu mar o seu horizonte, os seus astros descolgados do ceo ou cosidos, tamén teñen un precedente na poesía de Huidobro, como parece lóxico, xa que aporta un modelo moi novidoso, ademais cercan culturalmente.

Para rematar, Galicia non queda o marxe do proceso das vangardas, os nosos intelectuais, algúns, coñecen, comprenden e aceptan a revolución da arte, pero a práctica é esporádica, non supón unha liña de traballo elixida definitivamente, i e que a vangarda é antitradicionalista, e antinacionalista e antiestilista e en Galicia, as aspiracións diferenciais ocupan a mente dos intelectuais, adicados a crear e conservar unha tradición que engrosara a diferencia, que robustecese o concepto de país. A vangarda, nihilista, que tende a súa propia aniquilación non resultaba posible para acadar unha serie de necesidades antropolóxicas de arraigo.

"Cfr. Correspondencia, ed. cit.

"CUADERNOS DE ESTUDIOS GALLEGOS", Tomo XLVI, Fascículo 111, Santiago 1999. 